\title{
Solar Light Absorption Property of Nano-Structured Silver Layer and Application to Photo-Thermal Energy Conversion Coating
}

\author{
Masato Nishimura ${ }^{* 1}$ and Takashi Ishiguro $* 2$ \\ Department of Electrical Engineering, Nagaoka University of Technology, Nagaoka 940-2188, Japan
}

Nano-structured Ag layers with the thickness in a range of $d_{\mathrm{Ag}}=0.9-24 \mathrm{~nm}$ sandwiched between $\mathrm{MgO}$ layers are formed by rf sputtering. The morphology of nano-structured Ag is observed by the transmission electron microscope. Then the optical property is measured in a range of wavelength of $0.24-2.6 \mu \mathrm{m}$, which covers the solar energy spectrum. Several characteristics are recognized. For example, the nanostructured Ag layer having the intermediate morphology between the nano-particle and the continuous film shows the effective optical property in absorbing solar spectrum, such as large absorptance not only at visible region but also at near-infrared region. Moreover, it is found that the nano-structured $\mathrm{Ag}$ layers with $d_{\mathrm{Ag}} \leqq 5.4 \mathrm{~nm}$ and with $d_{\mathrm{Ag}} \geqq 24 \mathrm{~nm}$ are thermally stable at $673 \mathrm{~K}$, but those with $d_{\mathrm{Ag}}=6.3-13.5 \mathrm{~nm}$ are thermally unstable. In order to utilize the advantageous characteristics of the nano-structured Ag layers for the solar absorber coating, the optical constant of each layer is experimentally evaluated. Then the selective solar absorber coating with functional graded structure made of all nano-structured Ag layers is designed. The fabricated coating shows the high-performance such as the photo-thermal conversion efficiency of 0.72 for air mass 1.5 at an operating temperature of $373 \mathrm{~K}$, the thermal stability as well.

(Received March 18, 2002; Accepted June 5, 2002)

Keywords: nano-structure, nano-particle, thin film, mesoscopic morphology, photo-thermal energy conversion, selective solar absorber, silver, magnesium oxide

\section{Introduction}

It is well known that the nano-structured metallic film shows diversity of optical property as its thickness varies in the scale of nanometer. ${ }^{1)}$ One of the reasons is due to the discontinuity of the film morphology. For example, metallic fine particles such as Ag or Au fabricated by just metal deposition on a substrate ${ }^{2)}$ or by co-evaporation and/or cosputtering with dielectric ${ }^{3)}$ show a large absorption peak in the visible light region. This absorption phenomenon was first qualitatively explained by using a parameter of the volume fraction of metallic spheres in the medium. ${ }^{4)}$ Since then the theory has been improved by introducing several factors such as shape and size of particles ${ }^{2,3)}$ and interaction between them. ${ }^{5,6)}$ However, there is no theory that it can reproduce the observed optical constants quantitatively. From the viewpoint of application, the morphology of the dispersed metallic fine particles has been applied to, e.g., the photo-thermal energy conversion coating $^{7-12)}$ or the surface analysis using the attenuated total reflection (ATR) method. ${ }^{13,14)}$ The studies already made concerned mainly about two typical morphologies of both the fine particle and the continuous film. In other words, the quantitative evaluation of the systematic change in optical constant from the fine particle to the continuous film has not been adequately clear yet. Therefore we focus on the intermediate nano-structured morphology between the morphology of two dimensionally dispersed nano-particles and the morphology of continuous thin film. As an example, the welldefined $\mathrm{MgO} / \mathrm{Ag} / \mathrm{MgO}$ sandwiched structure including different nano-structured $\mathrm{Ag}$ layer has been investigated in this study. In order to utilize the properties of the nano-structured Ag layers for the design of solar absorber coating, optical constants and thermal stability of them have been systematically

\footnotetext{
${ }^{* 1}$ Graduate Student, Nagaoka University of Technology.

*2E-mail: ishiguro@ vos.nagaokaut.ac.jp
}

evaluated. Based on these results, a selective solar absorber coating with functionally graded laminated nano-structure is intentionally designed and fabricated. Then, its usefulness for the solar absorber coating is confirmed.

\section{Experiment}

The vacuum system of the sputtering apparatus consisted of a diffusion pump. The base pressure of the system was less than $2.7 \times 10^{-4} \mathrm{~Pa}$. Ag films were deposited by rf sputtering a water-cooled $100 \mathrm{~mm}$ diameter $\mathrm{Ag}$ target (99.99\%). $\mathrm{MgO}$ films were also deposited in a same chamber by using rf magnetron sputtering a water-cooled $100 \mathrm{~mm}$ diameter single-crystal $\mathrm{MgO}$ target. Using $\mathrm{Ar}$ gas (99.9995\%) at $0.53 \mathrm{~Pa}$, deposition of $\mathrm{MgO}$ and $\mathrm{Ag}$ were performed at $100 \mathrm{~W}$ and $150 \mathrm{~W}$ respectively. Deposition rate of $\mathrm{MgO}$ film and $\mathrm{Ag}$ film were $3.5 \mathrm{~nm} / \mathrm{min}$ and $7.7 \mathrm{~nm} / \mathrm{min}$, respectively.

The water-cooled substrate of Corning \#7059 glass with a thickness of $0.70 \mathrm{~mm}$ was used for measurement of the optical property. The water-cooled amorphous carbon film with a thickness of $25 \mathrm{~nm}$ on $\mathrm{Cu}$ mesh was also used for the substrate for the transmission electron microscopy (TEM) (JEOL, JEM200CX) observation in a plane view.

The optical properties of the films in a range of wavelength $(\lambda)=0.24-2.60 \mu \mathrm{m}$ were measured by using an ultraviolet-visible-near-infrared spectrometer (Shimadzu Co., UV-3100PC). At an infrared wavelength region of 2.17$25 \mu \mathrm{m}$, the measurement was performed by using Fourier transform infrared (FT-IR) spectrometer (JASCO, FT/IR7300). The relation between optical quantities was as follows. The incident light energy on a surface normal of the specimen changes into a sum of the backward reflection $\left(R_{0}\right)$, the forward transmission $\left(T_{0}\right)$, and the energy absorptance $(A)$ by specimen itself. Then, the rule of energy conservation is represented by $1=T_{0}+R_{0}+A$. In order to distinguish 
the incidence direction to a specimen having the structure of film/substrate, the superscript of " fil" for the incidence on film surface or the superscript of "sub" for the incidence on substrate will be used. The reflectance $\left(R_{0}\right)$ was evaluated by measuring the reflectance at an incidence angle of $12^{\circ}$.

In order to confirm the thermal stability of the specimens, they were annealed at $673 \mathrm{~K}$ in a vacuum of $2.7 \times 10^{-3} \mathrm{~Pa}$ by using an infrared furnace (ULVAC Sinku-Riko Mila-3000).

\section{Results and Discussion}

\subsection{Optical properties of $\mathrm{MgO} / \mathrm{Ag} / \mathrm{MgO}$ films and their morphologies}

Figure 1 shows the wavelength dependence of the transmittance $\left(T_{0}^{\mathrm{fil}}\right)$ of $\mathrm{MgO}\left(d_{2 \mathrm{MgO}}=4.5 \mathrm{~nm}\right) / \mathrm{Ag}\left(d_{\mathrm{Ag}}\right) / \mathrm{MgO}\left(d_{1 \mathrm{MgO}}=\right.$ $4.5 \mathrm{~nm}$ ) on the \#7059 glass substrate as a function of deposited thickness of $d_{\mathrm{Ag}}$, which is simply estimated by the deposition rate of Ag. Here $d_{1 \mathrm{MgO}}$ and $d_{2 \mathrm{MgO}}$ are the first and the second deposited respective $\mathrm{MgO}$ thickness estimated by the deposition rate of $\mathrm{MgO}$. The $d_{\mathrm{Ag}}$ varies in a range from $0.9 \mathrm{~nm}$ to $24 \mathrm{~nm}$. The $T_{0}^{\text {fil }}$ of $d_{\mathrm{Ag}}=0 \mathrm{~nm}$ is also plotted for a reference. All of the spectra of $\mathrm{MgO} / \mathrm{Ag} / \mathrm{MgO} / \# 7059$ glass show the relative maximum at around $\lambda=0.3-0.4 \mu \mathrm{m}$. It is deduced that the dielectric constant of $\mathrm{Ag}$ close to zero at $\lambda=0.33 \mu \mathrm{m} .{ }^{15,16)}$ In addition, $T_{0}^{\text {fil }}$ decreases sharp at $\lambda \leqq 0.3 \mu \mathrm{m}$. This is due to the intrinsic character of the \#7059 glass substrate. The wavelength dependence of $T_{0}^{\mathrm{fil}}$ changes systematically with increasing $d_{\mathrm{Ag}}$. It may, however, be presumed that all of the spectra are classified into three groups as follows, $A$-group $\left(d_{\mathrm{Ag}}=0.9-2.7 \mathrm{~nm}\right), B$-group $\left(d_{\mathrm{Ag}}=3.6-5.4 \mathrm{~nm}\right)$, and $C$-group $\left(d_{\mathrm{Ag}} \geqq 7.2 \mathrm{~nm}\right)$. In the $A$-group, $T_{0}^{\text {fil }}$ shows minimum at the region of visible light, then reaches toward about 0.9 at near-infrared region. The $T_{0}^{\text {fil }}$ of the $B$-group has both of a shallow relative minimum or a saddle slope at $\lambda=0.6-1.0 \mu \mathrm{m}$ and a flat or a gentle slope at near-infrared region. In the third, the $T_{0}^{\text {fil }}$ of the $C$ group has both of a maximum at around $\lambda=0.3-0.4 \mu \mathrm{m}$ and a monotonic decline at longer wavelength region. The $T_{0}^{\text {fil }}$ of $d_{\mathrm{Ag}}=6.3 \mathrm{~nm}$ shows features common to the $B$-group and the C-group.

Figure 2 shows the wavelength dependence of the reflectance $\left(R_{0}^{\mathrm{fil}}\right)$. As $d_{\mathrm{Ag}}$ increases up to $2.7 \mathrm{~nm}$, i.e., in the $A$-group, $R_{0}^{\text {fil }}$ shows a relative maximum at the region of visible light. Then $R_{0}^{\text {fil }}$ of the $B$-group show a plateau and/or a slope at near-infrared region. The value of $R_{0}^{\text {fil }}$ of the $B$-group keeps low less than about 0.2. As $d_{\mathrm{Ag}}$ increases more than $6.3 \mathrm{~nm}, R_{0}^{\text {fil }}$ increases systematically and closes to the value of $\mathrm{Ag}$ of bulk ${ }^{15)}$ at the visible and near-infrared regions. The reason of the relative minimum at $\lambda \sim 0.3 \mu \mathrm{m}$ indicated by a downward arrow in Fig. 2 is thought to be that the dielectric function of $\mathrm{Ag}$ closes to zero at $\lambda=0.33 \mu \mathrm{m} .{ }^{15,16)}$

In order to determine the wavelength dependence of optical constant of each film as will be calculated later, one more independently observed value is necessary. Therefore, as shown in Fig. 3, the wavelength dependence of the reflectance for an incidence on the substrate side $\left(R_{0}^{\mathrm{sub}}\right)$ of $\mathrm{MgO}(4.5 \mathrm{~nm}) / \mathrm{Ag}\left(d_{\mathrm{Ag}}\right) / \mathrm{MgO}(4.5 \mathrm{~nm}) / \# 7059$ glass substrate as a function of $d_{\mathrm{Ag}}$ is observed. The tendency of the variation of $R_{0}^{\text {sub }}$ in Fig. 3 is similar to the variation of $R_{0}^{\mathrm{fil}}$ in

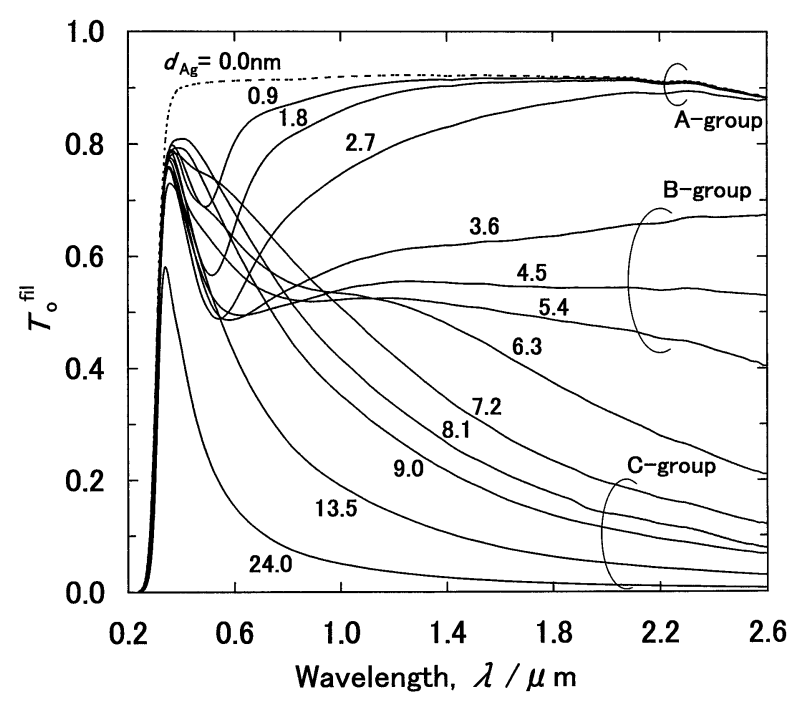

Fig. 1 Film thickness $\left(d_{\mathrm{Ag}}\right)$ dependence of the forward transmittance $\left[T_{0}^{\text {fil }}(\lambda)\right]$ of the film of $\mathrm{MgO}(4.5 \mathrm{~nm}) / \mathrm{Ag}\left(d_{\mathrm{Ag}}\right) / \mathrm{MgO}(4.5 \mathrm{~nm})$ on the \#7059 glass substrate.

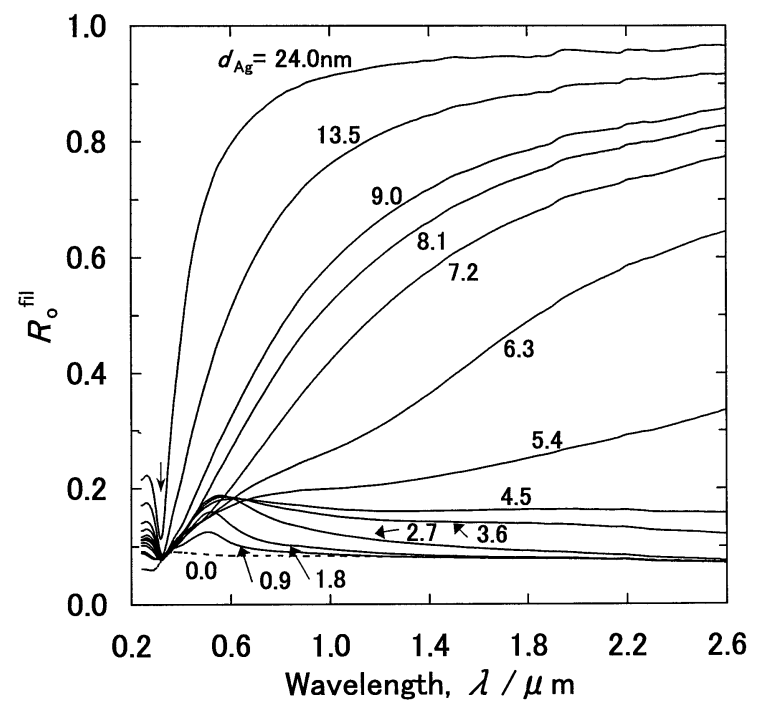

Fig. 2 Film thickness $\left(d_{\mathrm{Ag}}\right)$ dependence of the backward reflectance for the incidence on the exposed surface side $\left[R_{0}^{\text {fil }}(\lambda)\right]$ of the film of $\mathrm{MgO}(4.5 \mathrm{~nm}) / \mathrm{Ag}\left(d_{\mathrm{Ag}}\right) / \mathrm{MgO}(4.5 \mathrm{~nm})$ on the \#7059 glass substrate.

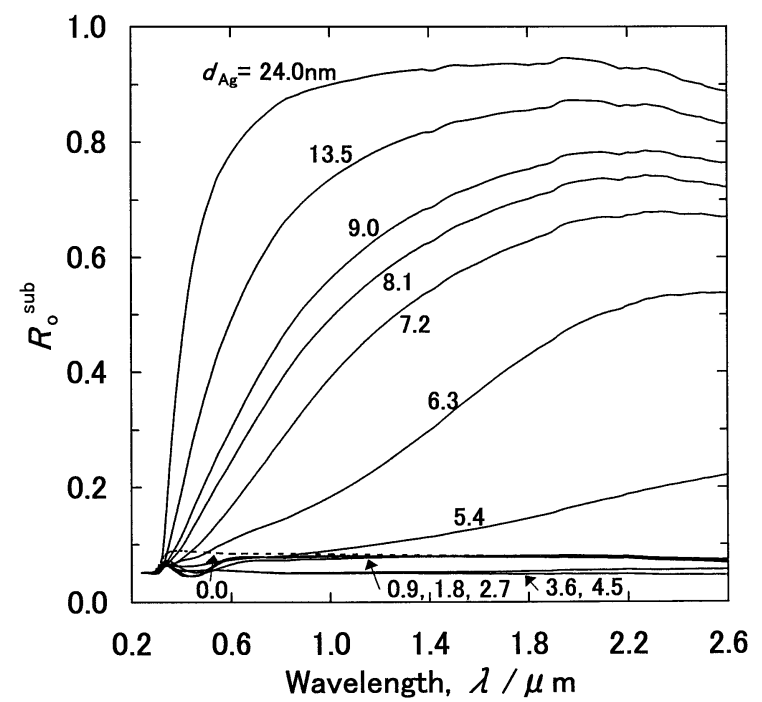

Fig. 3 Film thickness $\left(d_{\mathrm{Ag}}\right)$ dependence of the backward reflectance for the incidence on the substrate side $\left[R_{0}^{\mathrm{sub}}(\lambda)\right]$ of the film of $\mathrm{MgO}(4.5 \mathrm{~nm}) / \mathrm{Ag}\left(d_{\mathrm{Ag}}\right) / \mathrm{MgO}(4.5 \mathrm{~nm})$ on the \#7059 glass substrate. 


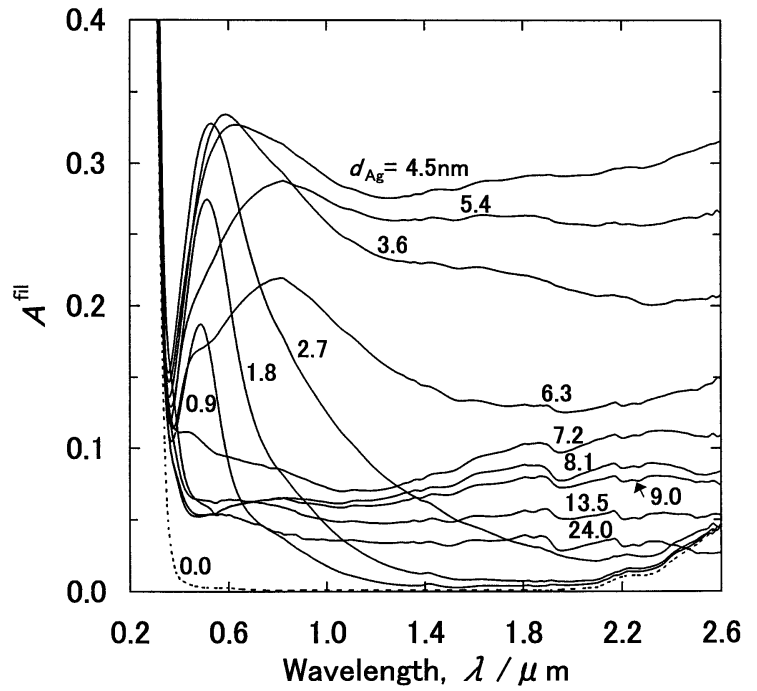

Fig. 4 Wavelength dependence of the energy absorptance $\left[A^{\text {fil }}(\lambda)=\right.$ $\left.1-T_{0}^{\text {fil }}(\lambda)-R_{0}^{\text {sub }}(\lambda)\right]$ for the incidence on the exposed surface of the film of $\mathrm{MgO}(4.5 \mathrm{~nm}) / \mathrm{Ag}\left(d_{\mathrm{Ag}}\right) / \mathrm{MgO}(4.5 \mathrm{~nm})$ on the \#7059 glass substrate, as a function of $d_{\mathrm{Ag}}$.

\section{Fig. 2.}

Based on the results of $T_{0}^{\mathrm{fil}}(\lambda)$ and $R_{0}^{\mathrm{fil}}(\lambda)$, the wavelength dependence of energy absorptance $\left[A^{\mathrm{fil}}(\lambda)=1-T_{0}^{\mathrm{fil}}(\lambda)-\right.$ $\left.R_{0}^{\mathrm{fil}}(\lambda)\right]$ is obtained as shown in Fig. 4. Here the sudden increase at $\lambda \leqq 0.3 \mu \mathrm{m}$ is due to the own property of the \#7059 glass substrate. The $A^{\text {fil }}$ of the $A$-group $\left(d_{\mathrm{Ag}}=0.9-2.7 \mathrm{~nm}\right)$ shows peak at visible region where, as increasing $d_{\mathrm{Ag}}$, the value of relative maximum increases, and then the position of the peak shifts to longer wavelength. ${ }^{4)}$ On the other hand, the $A^{\text {fil }}$ of the $C$-group $\left(d_{\mathrm{Ag}} \geqq 7.2 \mathrm{~nm}\right)$ shows almost constant value less than about 0.1 at $\lambda=0.3-2.6 \mu \mathrm{m}$. This reason is thought to be the systematic decrease of $T_{0}^{\text {fil }}$ (see Fig. 1) in cooperation with the systematic increase of $R_{0}^{\text {fil }}$ (see Fig. 2) takes place at the same time with increasing $d_{\mathrm{Ag}}$. In contrast with the $A^{\text {fil }}(\lambda)$ of the $A$-group and/or the $C$-group, it should be emphasized that the $A^{\text {fil }}$ of the $B$-group $\left(d_{\mathrm{Ag}}=3.6-5.4 \mathrm{~nm}\right)$ has value of energy absorptance as large as $0.2-0.3$ at the visible and near-infrared regions. This characteristic is useful to absorb solar energy spectrum, which distributes widely in $\lambda=0.30-2.45 \mu \mathrm{m}$. Then the solar energy absorptance $(\alpha)^{17)}$ is calculated by

$$
\alpha=\int_{\lambda=0.24 \mu \mathrm{m}}^{2.6 \mu \mathrm{m}} A^{\mathrm{fil}}(\lambda) \cdot S(\lambda) \cdot d \lambda / \int_{\lambda=0.24 \mu \mathrm{m}}^{2.6 \mu \mathrm{m}} S(\lambda) \cdot d \lambda,
$$

where $S(\lambda)$ is the spectral solar radiance with the proper air mass number. ${ }^{18)}$ The $d_{\mathrm{Ag}}$ dependence of $\alpha$ for the air mass 1.5 (AM1.5) is shown in Fig. 5 where $\alpha$ increases with $d_{\mathrm{Ag}}$, reaches a maximum value of 0.295 at $4.5 \mathrm{~nm}$, and decreases via a value of 0.18 at $6.3 \mathrm{~nm}$, and then reaches to an almost constant value of 0.06 thereafter. Although the $\alpha$ corresponding to the AM1 and AM2 are also calculated, the result of the numerical value of $\alpha\left(d_{\mathrm{Ag}}\right)$ of them are almost same as $\alpha\left(d_{\mathrm{Ag}}\right)$ of AM1.5.

In order to observe the morphology of $\mathrm{Ag}$ in nanometer scale corresponding to the above optical properties, the three layered structure of $\mathrm{MgO}(4.5 \mathrm{~nm}) / \mathrm{Ag}\left(d_{\mathrm{Ag}}\right) / \mathrm{MgO}(4.5 \mathrm{~nm})$ is

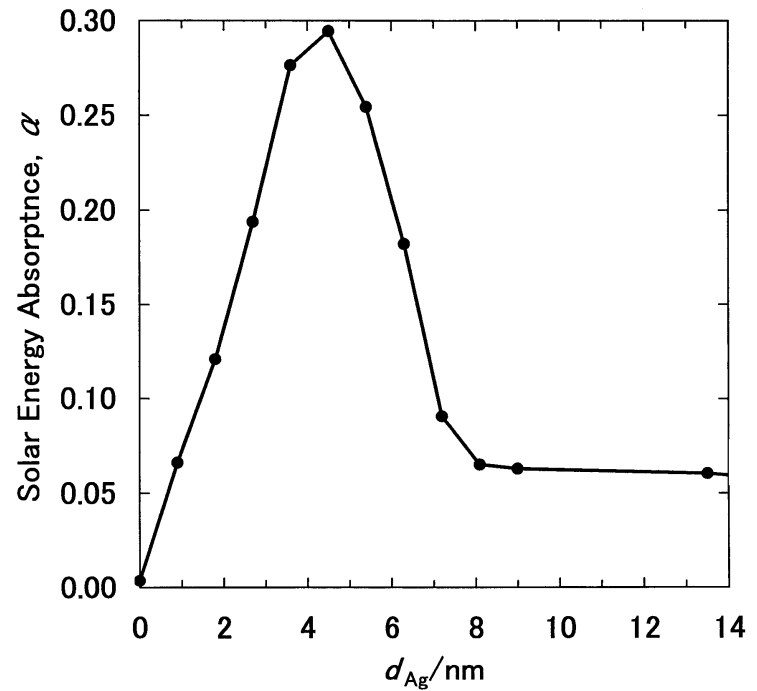

Fig. 5 Solar energy absorptance $(\alpha)$ for the film of $\operatorname{MgO}(4.5 \mathrm{~nm}) / \mathrm{Ag}\left(d_{\mathrm{Ag}}\right) /$ $\mathrm{MgO}(4.5 \mathrm{~nm})$ on the \#7059 glass substrate at AM1.5 conditions, as a function of $d_{\mathrm{Ag}}$.

fabricated on the amorphous carbon mesh. The TEM bright field plan view images of them are shown in Fig. 6 where the regions with dark contrast correspond to the buried $\mathrm{Ag}$ in $\mathrm{MgO}$ matrix. Figures 6(a), (b) and (c), which belong to the $A$-group, show the morphology of the isolated ultra fine particles or the dispersed nano-particles. The form of particles is rounded and their diameter increases with $d_{\mathrm{Ag}}$. Figures 6(h), (i) and (j), which belong to the $C$-group, show the morphology of almost continuous polycrystalline thin film. In contrast with the morphologies of the $A$-group and/or of the $C$-group, Figs. 6(d), (e) and (f), which belong to the $B$-group, show the intermediate morphology between the dispersed nanoparticles and the continuous thin film. Here, as increasing $d_{\mathrm{Ag}}$, the nano-particles are connected with each other, then form the insular film (Figs. 6(d) and (e)), and then change into the maze-cracked thin film (Fig. 6(f)), which changes into continuous film of the $C$-group via a transient form of Fig. 6(g). By considering corresponding optical properties, it becomes clear that the nano-structured films such as the nanoparticle, the insular film and the maze-cracked thin film are promising candidates for the elements to fabricate the solar absorber coating. ${ }^{7-12)}$

\subsection{Complex refractive indices and thermal stability}

In general, the solar absorber coating requires a high solar energy absorptance and a concomitant low thermal emittance. ${ }^{19)}$ To achieve the surface with such spectral selectivity, the combination of the above nano-structured films is one of the possible ways. Therefore the complex refractive indices $(N(\lambda)=n(\lambda)-i k(\lambda))$ where $n$ and $k$ are refractive index and extinction coefficient, respectively, has been evaluated. ${ }^{20)}$ Firstly the complex indices of \#7059 glass are obtained by other independent experiment. Secondary the complex indices of $\mathrm{MgO}$ are calculated from the observed $T_{0}^{\text {fil }}, R_{0}^{\text {fil }}$ and $R_{0}^{\text {sub }}$ of the specimen of $\mathrm{MgO} / \# 7059$ glass with a proper thickness of $\mathrm{MgO}$. In the case of the $\mathrm{Ag}$ layer with the discontinuous morphologies such as nano-particle, insular film and maze-cracked film, the corresponding opti- 

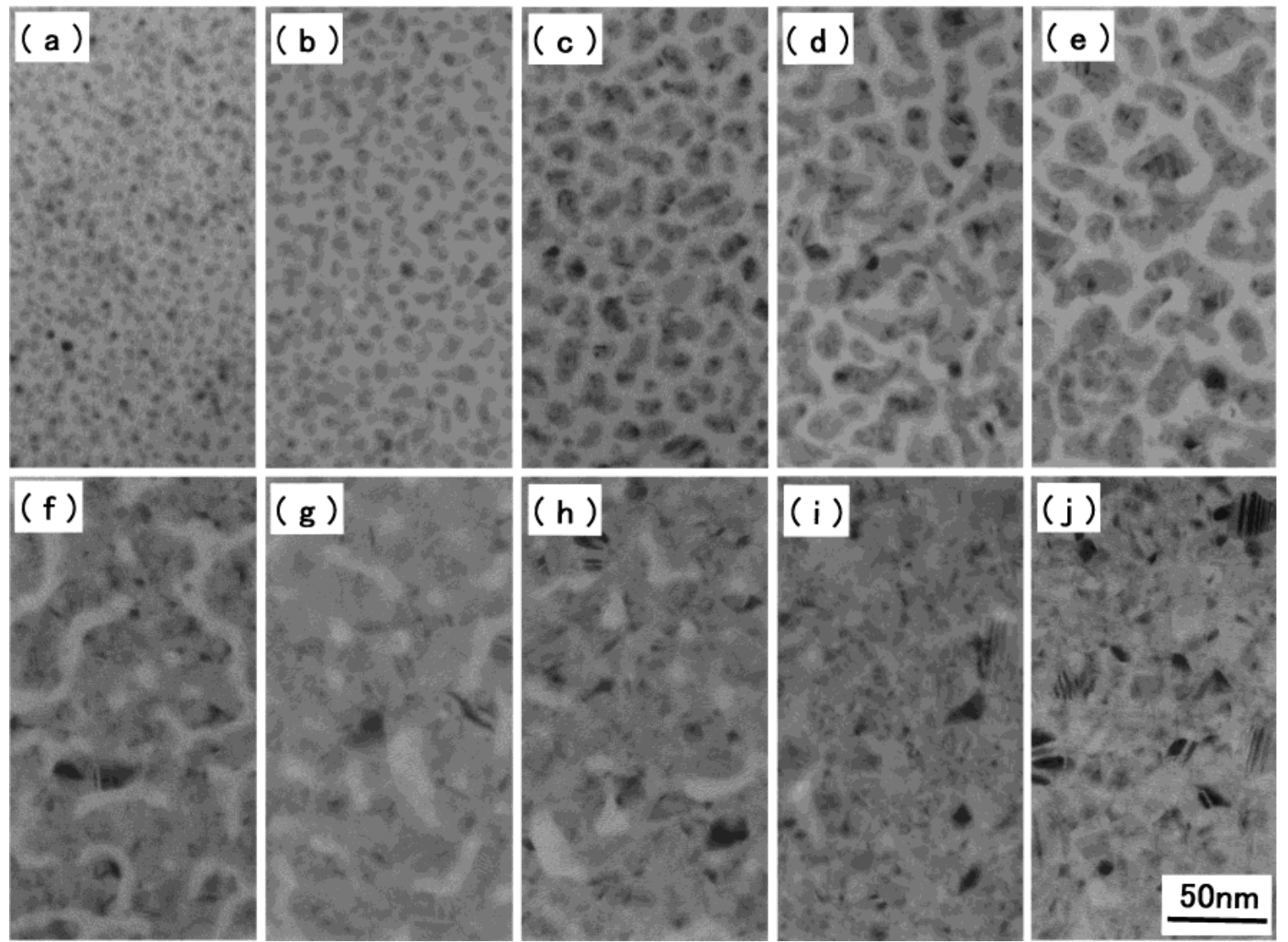

Fig. 6 Bright field transmission electron microscopy images of the film of $\mathrm{MgO}(4.5 \mathrm{~nm}) / \mathrm{Ag}\left(d_{\mathrm{Ag}}\right) / \mathrm{MgO}(4.5 \mathrm{~nm})$ on amorphous carbon film. The values of $d_{\mathrm{Ag}}$ of (a), (b), (c), (d), (e), (f), (g), (h), (i) and (j) are $0.9,1.8,2.7,3.6,4.5,5.4,6.3,7.2,8.1$ and $9.0 \mathrm{~nm}$, respectively.

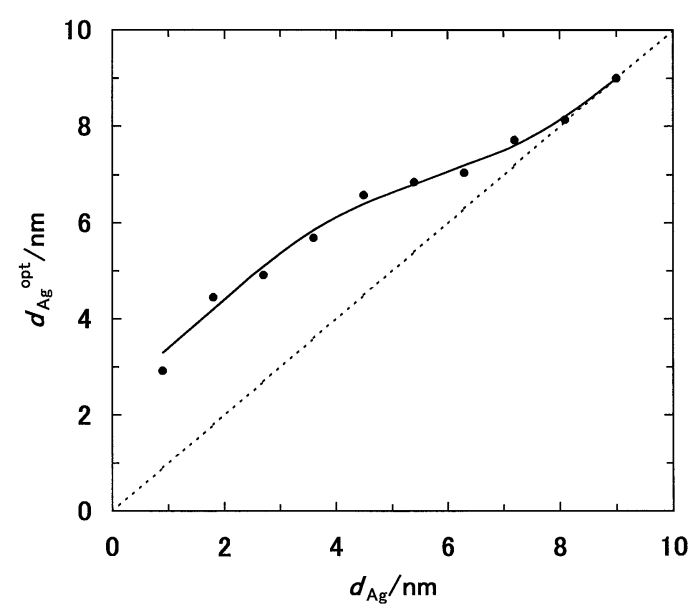

Fig. 7 Deposited $\mathrm{Ag}$ layer thickness $\left(d_{\mathrm{Ag}}\right)$ dependence of the optical $\mathrm{Ag}$ layer thickness $\left(d_{\mathrm{Ag}}^{\mathrm{opt}}\right)$.

cal thickness $\left(d_{\mathrm{Ag}}^{\mathrm{opt}}\right)$ is not same as the deposited thickness of $d_{\mathrm{Ag}}$. We assumed the optical thickness of respective layers to be $\mathrm{MgO}\left(d_{2 \mathrm{MgO}}^{\mathrm{opt}}\right) / \mathrm{Ag}\left(d_{\mathrm{Ag}}^{\mathrm{opt}}\right) / \mathrm{MgO}\left(d_{1 \mathrm{MgO}}^{\mathrm{opt}}=d_{1 \mathrm{MgO}}=\right.$ $4.5 \mathrm{~nm}) / \# 7059$ glass substrate. Here in the layer of $\operatorname{Ag}\left(d_{\mathrm{Ag}}^{\mathrm{opt}}\right)$, the inter-spaces of the Ag nano-particles and the gaps in the maze-cracked Ag film are filled by the part of the covered $\mathrm{MgO}\left(d_{2 \mathrm{MgO}}\right)$. In order to obtain $d_{\mathrm{Ag}}^{\text {opt }}$, the area fraction of $\mathrm{Ag}$ region $(f)$ is evaluated from the plane view TEM images such as Fig. 6. Then the net thickness of the discontinuous

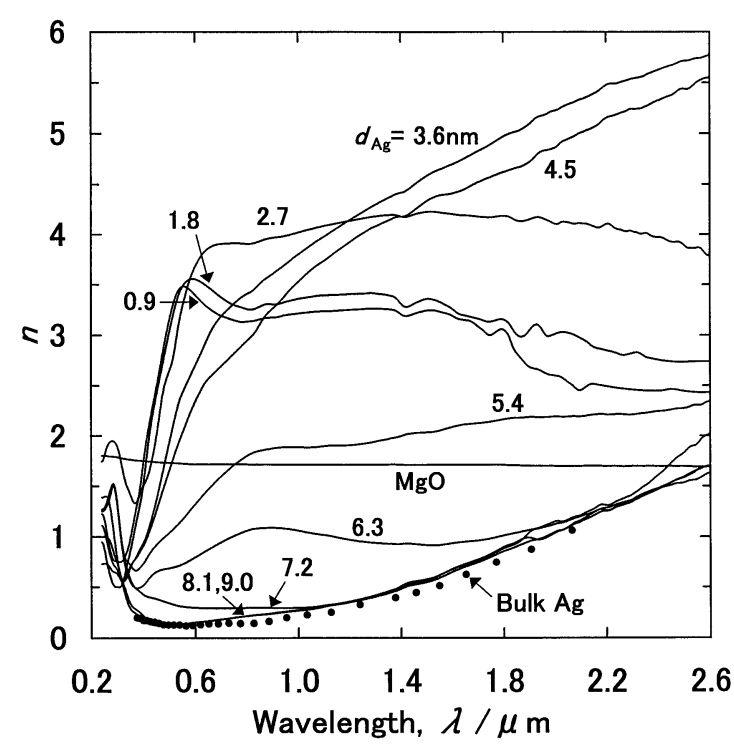

Fig. 8 Wavelength dependence of the real part of complex refractive indices of $n(\lambda)-i k(\lambda)$ for the $\mathrm{Ag}$ layer having $d_{\mathrm{Ag}}^{\mathrm{opt}}$ as a function of $d_{\mathrm{Ag}}$. $n(\lambda)$ of $\mathrm{MgO}$ and bulk $\mathrm{Ag}$ are also plotted.

Ag layer, i.e., optical thickness, is defined by $d_{\mathrm{Ag}}^{\mathrm{opt}}=d_{\mathrm{Ag}} / f$. And then $d_{2 \mathrm{MgO}}^{\mathrm{opt}}=d_{2 \mathrm{MgO}}+d_{\mathrm{Ag}}-d_{\mathrm{Ag}}^{\mathrm{opt}}$. The result of $d_{\mathrm{Ag}}^{\mathrm{opt}}$ is shown in Fig. 7 as a function of $d_{\mathrm{Ag}}$. Based on the above optical thickness, the wavelength dependence of the complex refractive indices of the layer with the thickness of $d_{\mathrm{Ag}}^{\mathrm{opt}}$ is calculated. Figure 8 shows the $d_{\mathrm{Ag}}$ dependence of the refractive 


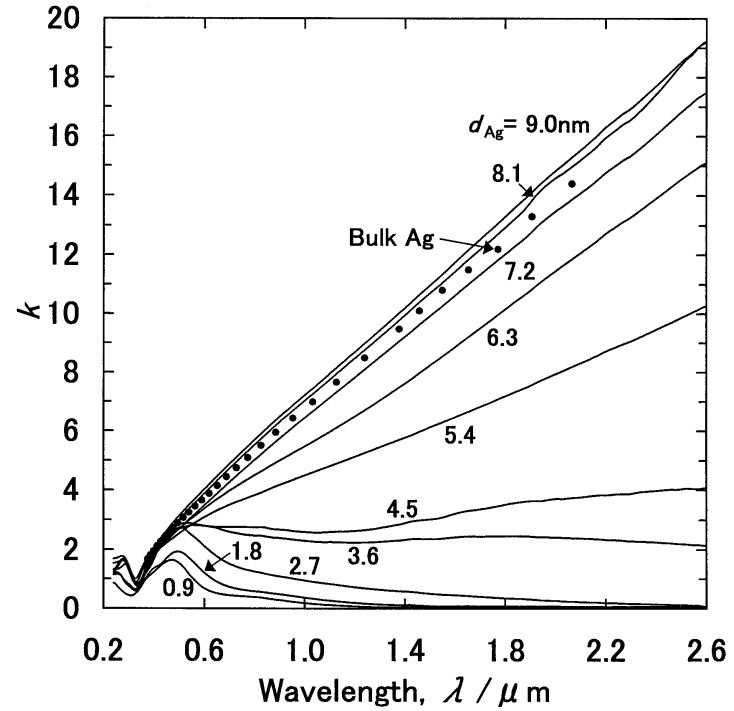

Fig. 9 Wavelength dependence of the imaginary part of complex refractive indices of $n(\lambda)-i k(\lambda)$ for the Ag layer having $d_{\mathrm{Ag}}^{\mathrm{opt}}$ as a function of $d_{\mathrm{Ag}}$. $k(\lambda)$ of bulk Ag is also plotted.

index of $n(\lambda)$. The $n(\lambda)$ of the $A$-group $\left(d_{\mathrm{Ag}}=0.9-2.7 \mathrm{~nm}\right)$ increases with $\lambda$ in the visible region, then remains own values to be $2.5-4$ in the near-infrared region. The $n(\lambda)$ of the $B$-group $\left(d_{\mathrm{Ag}}=3.6-5.4 \mathrm{~nm}\right)$ increases with $\lambda$ in the visible region, then gradually increases in the near-infrared region although the value of $n$ at the same $\lambda$ decreases with $d_{\mathrm{Ag}}$. The $n(\lambda)$ of the $C$-group $\left(d_{\mathrm{Ag}}=7.2-9.0 \mathrm{~nm}\right)$ has almost same values of the bulk Ag which is plotted by dots ${ }^{16)}$ in Fig. 8. The $n(\lambda)$ of $\mathrm{MgO}$ does not change drastically with $\lambda$ and remains own value within a range of 1.7-1.8. Figure 9 shows the $d_{\mathrm{Ag}}$ dependence of the extinction coefficient of $k(\lambda)$, which has a tendency of systematic increase in the near-infrared region with increasing $d_{\mathrm{Ag}}$, then approaches the values of the bulk Ag plotted by dots. ${ }^{16)}$ The $k(\lambda)$ of $\mathrm{MgO}$ has the value less than $1 \times 10^{-3}$. Here we have obtained the correspondence between $n(\lambda)-i k(\lambda)$ and $d_{\mathrm{Ag}}$.

The nano-structured films must be thermally stable, if we intend to apply them to solar absorber coating, or photothermal energy conversion film. Therefore these films are annealed at $673 \mathrm{~K}$ in a vacuum for 1 hour and following 9 hours. The temperature of $673 \mathrm{~K}$ is higher than the typical ultimate temperature of the high performance solar absorber coating. ${ }^{17)}$ Figure 10 shows the typical comparison of $T_{0}^{\text {fil }}$ between before and after annealing $(673 \mathrm{~K}-1 \mathrm{~h})$ with different $d_{\mathrm{Ag}}$. The change of $T_{0}^{\mathrm{fil}}$ of the specimen with $d_{\mathrm{Ag}}=5.4 \mathrm{~nm}$ is within 0.03 , but the $T_{0}^{\text {fil }}$ of the specimen with $d_{\mathrm{Ag}}=6.3 \mathrm{~nm}$ drastically changes. Actually speaking, in the annealed specimen with $d_{\mathrm{Ag}}=6.3 \mathrm{~nm}$, the aggregation of Ag with a size of about a few micrometer on the surface is observed by an optical microscope. Furthermore, as a symbolic example, the time dependence of the change of $T_{0}^{\mathrm{fil}}(\lambda=1.5 \mu \mathrm{m})$ for the different $d_{\mathrm{Ag}}$ are shown in Fig. 11. It can be mentioned that the specimens with $6.3 \mathrm{~nm} \leqq d_{\mathrm{Ag}} \leqq 13.5 \mathrm{~nm}$ thermally unstable, and the specimens with $d_{\mathrm{Ag}} \leqq 5.4 \mathrm{~nm}$ and the specimen with $d_{\mathrm{Ag}}=24 \mathrm{~nm}$, which is continuous and thick enough, are thermally stable. One of the reasons for the instability is thought to be the cohesion of $\mathrm{Ag}$. And then a reason for the stability is thought to be the morphology of isolated $\mathrm{Ag}$

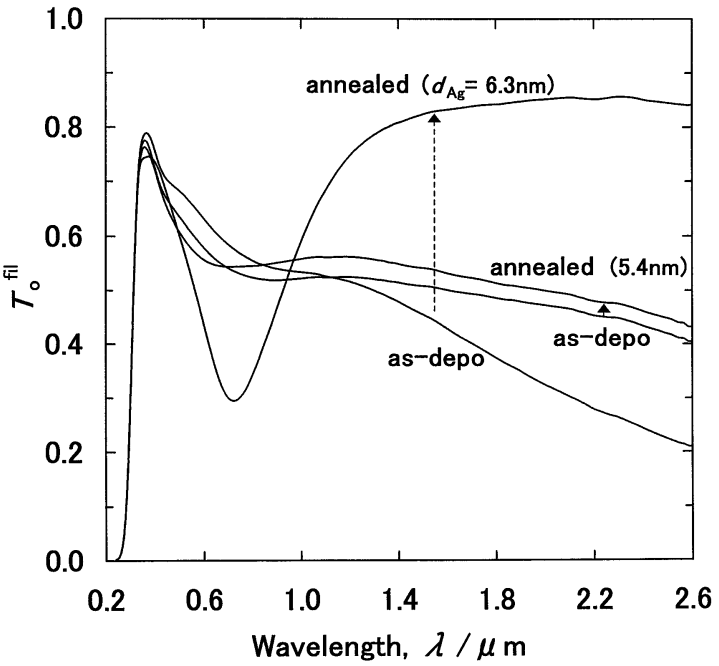

Fig. 10 Typical comparison of $T_{0}^{\text {fil }}$ between before and after annealing $(673 \mathrm{~K}-1 \mathrm{~h})$ with different $d_{\mathrm{Ag}}$ of $5.4 \mathrm{~nm}$ and $6.3 \mathrm{~nm}$.

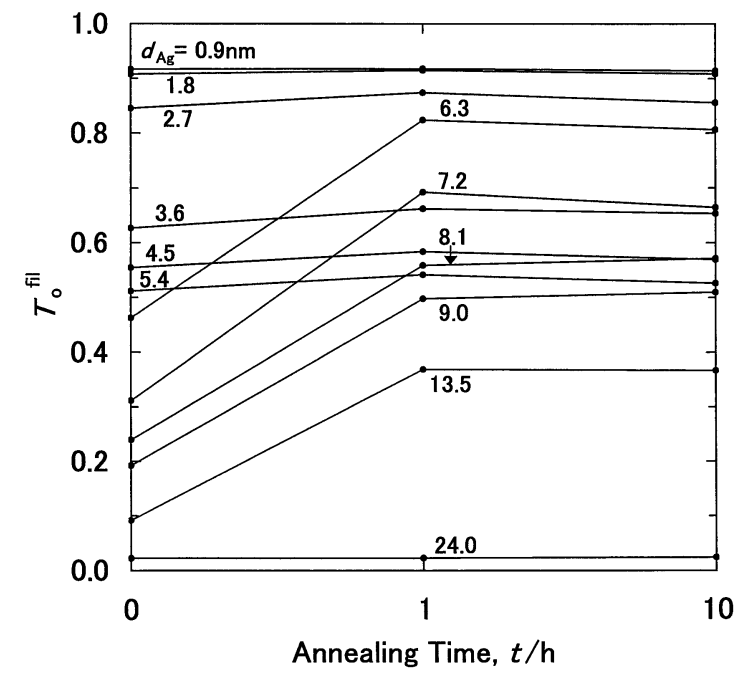

Fig. 11 Time dependence of the change of $T_{0}^{\text {fil }}$ at $\lambda=1.5 \mu \mathrm{m}$ by annealing at $673 \mathrm{~K}$ for the different $d_{\mathrm{Ag}}$.

nano-structures, e.g., nano-particles and/or insular discontinuous film structure. As the result, it can be concluded that the nano-structured Ag layers with $d_{\mathrm{Ag}} \leqq 5.4 \mathrm{~nm}$, i.e., $A$ - and $B$-groups, are possible to use for the elements of the solar absorber coating.

\subsection{An application to photo-thermal energy conversion film}

One of the requirements for the photo-thermal energy conversion film is the low thermal emittance, which is equivalent to the low energy absorptance at infrared region or the high reflectance at infrared region. Therefore the reflectance $\left(R_{0}^{\mathrm{fil}}\right)$ of the thermally stable candidates $\left(d_{\mathrm{Ag}} \leqq 5.4 \mathrm{~nm}\right)$ are measured even in the infrared region as shown in Fig. 12. Only the specimen of $d_{\mathrm{Ag}}=5.4 \mathrm{~nm}$ shows increase of $R_{0}^{\mathrm{fil}}$ with wavelength at infrared region. Then it is easily deduced that the lamination of the $\mathrm{Ag}$ layer with $d_{\mathrm{Ag}}=5.4 \mathrm{~nm}$ is more effective in enhancement of reflectance at infrared region.

Using all of the data obtained above, a typical model of the photo-thermal energy conversion film with a functionally graded structure ${ }^{21-23)}$ made of all nano-structured Ag layers, 


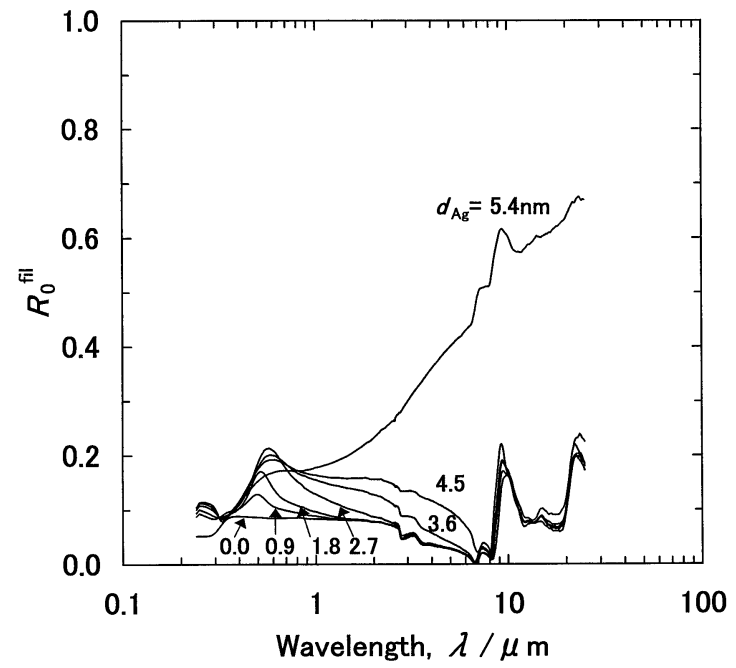

Fig. 12 Wavelength dependence of $R_{0}^{\text {fil }}$ of the annealed $(673 \mathrm{~K}-10 \mathrm{~h})$ films with $d_{\mathrm{Ag}}$ of $0-5.4 \mathrm{~nm}$.

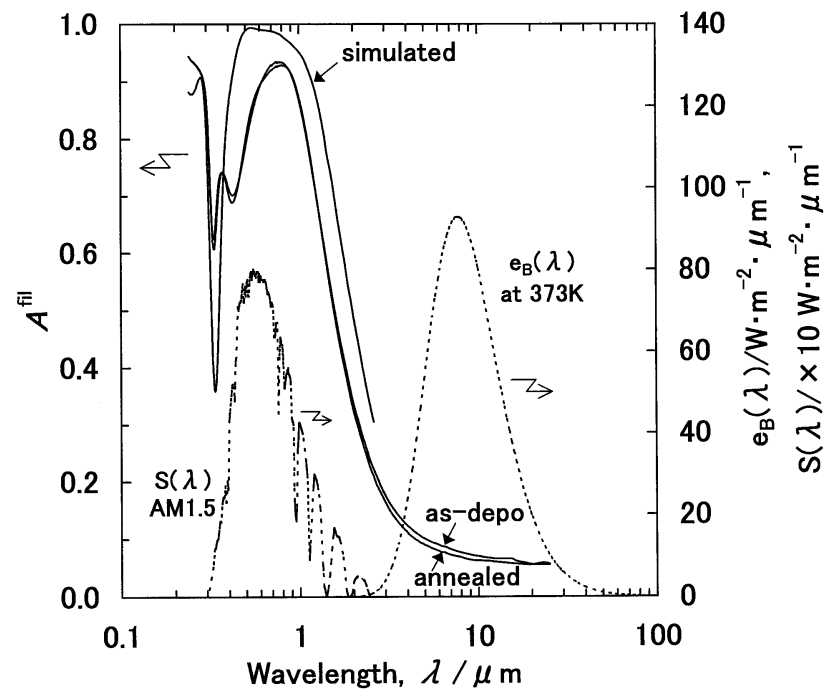

Fig. 13 Simulated $A^{\text {fil }}(\lambda)$ based on the model and observed $A^{\text {fil }}(\lambda)$ of before and after annealing of the film fabricated actually. $e_{\mathrm{B}}(\lambda)$ : the spectral blackbody emissive power at $373 \mathrm{~K}$, and $S(\lambda)$ : the spectral solar radiance of air mass 1.5 are plotted by broken lines.

i.e., $\mathrm{MgO}(63.6 \mathrm{~nm}) / \mathrm{Ag}(2.7 \mathrm{~nm}) / \mathrm{MgO}(9.1 \mathrm{~nm}) / \mathrm{Ag}(3.6 \mathrm{~nm}) /$ $\mathrm{MgO}(9.1 \mathrm{~nm}) / \mathrm{Ag}(4.5 \mathrm{~nm}) / \mathrm{MgO}(9.1 \mathrm{~nm}) /(\mathrm{Ag}(5.4 \mathrm{~nm}) /$ $\mathrm{MgO}(9.1 \mathrm{~nm}))_{8}$ on the \#7059 glass substrate is designed. Here, the aim of the laminated structure of $(\operatorname{Ag}(5.4 \mathrm{~nm}) /$ $\mathrm{MgO}(9.1 \mathrm{~nm}))_{8}$ is to realize both of the elimination of transmittance and the enhancement of reflectance at infrared region. The aim of the gradation by using nano-structured $\mathrm{Ag}$ layer with $d_{\mathrm{Ag}}=2.7-5.4 \mathrm{~nm}$ is a gradient-refractive index to reduce the reflectance of the incident light. The $\mathrm{MgO}$ with a thickness of $63.6 \mathrm{~nm}$ at the surface also contributes to an anti-reflection coating at around $\lambda=0.5 \mu \mathrm{m}$.

The simulated $A^{\mathrm{fil}}(\lambda)$ of the model is shown in Fig. 13. The observed $A^{\text {fil }}(\lambda)$ of the film fabricated actually based on the model reproduces well the tendency of the high energy absorptance at visible and near-infrared region, although the value is small a little bit compared with the simulated $A^{\text {fil }}(\lambda)$, and as might have been expected, the observed $A^{\text {fil }}(\lambda)$ shows the low energy absorptance at infrared region. In addition to such a spectral selectivity, it can be mentioned by compar-

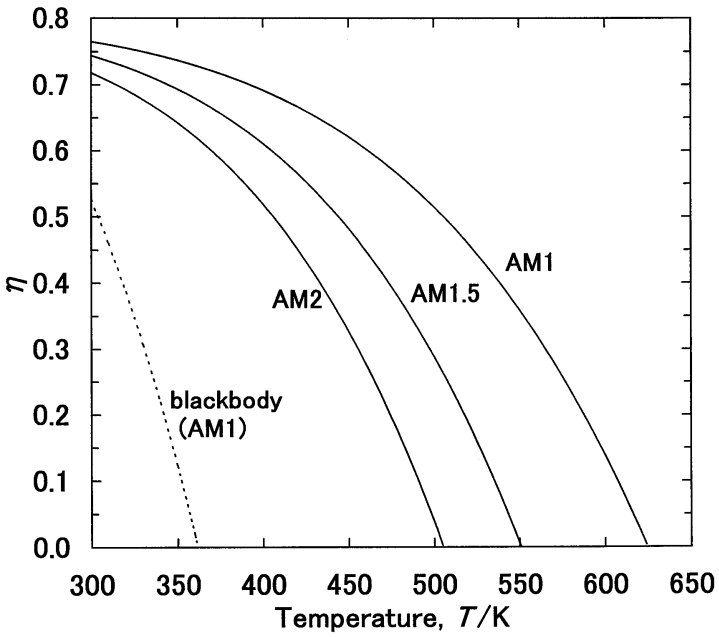

Fig. 14 Temperature dependence of photo-thermal energy conversion efficiency $\eta$ at AM1, AM1.5, and AM2 (solid lines). $\eta$ of blackbody at AM1 (dotted line).

ing the as-deposited $A^{\mathrm{fil}}(\lambda)$ and the annealed $A^{\mathrm{fil}}(\lambda)(673 \mathrm{~K}-$ $10 \mathrm{~h}$ ) that the fabricated film is thermally stable. Finally we evaluate its performance as a solar absorber coating. Using eq. (1), almost same value of $\alpha$ of 0.80 is obtained for the AM1, AM1.5, and AM2 respectively. The emissivity $(\varepsilon)^{24)}$ can be calculated as follows,

$\varepsilon=\int_{\lambda=0.24 \mu \mathrm{m}}^{25 \mu \mathrm{m}} A^{\mathrm{fil}}(\lambda) \cdot e_{\mathrm{B}}(\lambda, T) d \lambda / \int_{\lambda=0.24 \mu \mathrm{m}}^{25 \mu \mathrm{m}} e_{\mathrm{B}}(\lambda, T) d \lambda$,

where $e_{\mathrm{B}}(\lambda, T)$ (see e.g., Fig. 13) is the spectral blackbody emissive power at an temperature $T$, and $A^{\text {fil }}(\lambda)$ is energy absorptance of annealed specimen as shown in Fig. 13. The error in $\varepsilon$ due to the cut off at an upper limit of integration $(\lambda=25 \mu \mathrm{m})$ is estimated to be less than $0.1 \%$. Then the photo-thermal energy conversion efficiency $(\eta)^{17)}$ can be defined by

$$
\eta=\alpha-\varepsilon \sigma T^{4} / I
$$

where $\sigma$ and $I$ are the Stefan-Boltzmann constant and the solar flux intensity corresponding to the proper air mass number. The temperature dependence of $\eta(T)$ of the specimen with observed $A^{\text {fil }}(\lambda)$ at different irradiation intensities, e.g., AM1, AM1.5, and AM2, are shown by solid lines in Fig. 14 where $\eta(T)$ of blackbody surface at AM1 is also plotted by a dotted line. The ultimate temperatures of the specimen are estimated to be $624 \mathrm{~K}$ for AM1, $551 \mathrm{~K}$ for AM1.5, and $505 \mathrm{~K}$ for AM2 by taking a balance of $\alpha$ and $\varepsilon$ in eq. (3). These temperatures are naturally higher than $361 \mathrm{~K}$ of the blackbody at AM1. Our present trial product film has $\eta$ values of 0.72 for AM1, 0.66 for AM1.5, and 0.59 for AM2 at a typical operating temperature of $373 \mathrm{~K}$. These values of performance parameters are superior or comparable to the values of practically used blackchrome film, e.g., $\eta=0.51$, which is our estimation based on the parameters of the reference ( $\alpha=0.94$ and $\varepsilon=0.14$ under the conditions of $373 \mathrm{~K}$ and AM2). ${ }^{25)}$ Our present trial product has not been optimized yet, then leaves much to be desired. 


\section{Conclusion}

As an example of the application of nano-structure, the solar absorber coating having functional graded structure composed of the nano-structured Ag layers with different morphology has been fabricated. In order to design this coating, the thermal and optical characteristics of the well-defined $\mathrm{MgO} / \mathrm{Ag}\left(d_{\mathrm{Ag}}\right) / \mathrm{MgO}$ structure with different $d_{\mathrm{Ag}}$ were experimentally evaluated. It was revealed, as regards the thermal stability at the condition of $673 \mathrm{~K}-10 \mathrm{~h}$, that although the specimens with $d_{\mathrm{Ag}} \leqq 5.4 \mathrm{~nm}$ and with $d_{\mathrm{Ag}} \geqq 24 \mathrm{~nm}$ were thermally stable, but the specimens with $d_{\mathrm{Ag}}=6.3-13.5 \mathrm{~nm}$ were unstable. In other words, the nano-structured Ag layers could not always be utilized for the solar absorber coating from the viewpoint of thermal stability. It was also confirmed that the optical absorption of the nano-structured Ag layer varied from the resonance absorption at visible region to the metallic reflection through the broadened absorption at visible and near infrared regions as $d_{\mathrm{Ag}}$ increased. By using the optical measurement and the structural observation, the optical constants of nano-structured Ag layers were experimentally obtained. Then a selective solar absorber coating with thermal stability had been designed and made of all nano-structured Ag layers.

\section{Acknowledgments}

One of the authors (T.I.) was supported by a Grant-inAid for Science Research of the Ministry of Education, Culture, Sports, Science and Technology of Japan (Project No. 12650658 and 14550651).

\section{REFERENCES}

1) G. Rasigni and P. Rouard: J. Opt. Soc. Amer. 53 (1963) 604-612.

2) R. H. Doremus: J. Appl. Phys. 37 (1966) 2775-2781.

3) R. W. Cohen, G. D. Cody, M. D. Coutts and B. Abeles: Phys. Rev. B 8 (1973) 3689-3701.

4) J. C. Maxwell Garnett: Phil. Trans. R. Soc. Lond. A 203 (1904) 385420.

5) C. G. Granqvist and O. Hunderi: Phys. Rev. B 16 (1976) 3513-3534.

6) P. Sheng: Phys. Rev. Lett. 45 (1980) 60-63.

7) J. C. C. Fan and P. M. Zavracky: Appl. Phys. Lett. 29 (1976) 478-480.

8) D. R. McKenzie: Appl. Phys. Lett. 34 (1979) 25-28.

9) G. A. Nyberg and R. A. Buhrman: Appl. Phys. Lett. 40 (1982) 129-131.

10) G. A. Niklasson and C. G. Granqvist: J. Appl. Phys. 55 (1984) 33823410.

11) L. K. Thomas and C. Tang: Sol. Energy Mater. 18 (1989) 117-126.

12) Q. C. Zhang and D. R. Mills: J. Appl. Phys. 72 (1992) 3013-3021.

13) T. Kume, N. Nakagawa, S. Hayashi and K. Yamamoto: Solid State Commun. 93 (1995) 171-175.

14) S. Hayashi, T. Kume, T. Amano and K. Yamamoto: Jpn. J. Appl. Phys. 35 (1996) 331-334.

15) H. Ehrenreich and H. R. Philipp: Phys. Rev. 128 (1962) 1622-1629.

16) P. Winsemius, F. F. van Kampen, H. P. Lengkeek and C. G. van Went: J. Phys. F 6 (1976) 1583-1606.

17) Q. C. Zhang: Solar Energy Mater. \& Solar Cells 62 (2000) 63-74.

18) Solar Spectral Irradiance, 1 st edition, Intl. Commission of Illumination Publication, CIE TC2-17, Vienna, Austria (1989) pp. 25-28.

19) G. A. Niklasson and C. G. Granqvist: J. mater. Sci. 18 (1983) 34753534.

20) T. Ishiguro, M. Nishimura and T. Yamazaki: Jpn. J. Appl. Phys. 41 (2002) 292-300.

21) I. T. Ritchie and B. Window: Appl. Opt. 16 (1977) 1438-1443.

22) D. M. Trotter, Jr. and A. J. Sievers: Appl. Opt. 19 (1980) 711-728.

23) W. H. Southwell: Appl. Opt. 24 (1985) 457-460.

24) H. G. Craighead, R. E. Howard, J. E. Sweeney and R. A. Buhrman: Appl. Phys. Lett. 39 (1981) 29-31.

25) P. K. Gogna and K. L. Chopra: Thin Solid Films 63 (1979) 183-187. 